\title{
The role of risk factors in the incidence and recurrence of ectopic pregnancy
}

\author{
Catalina Diana Stanica, Adrian Neacsu, Romina Marina Sima, Raluca Gabriela Ioan \\ Department of Obstetrics and Gynecology, "Carol Davila" University of Medicine and Pharmacy, \\ Bucharest, Romania
}

\begin{abstract}
The increase in the incidence of ectopic pregnancy in the last 20 years, with the serious compromise of the woman's obstetric future and the life-threatening complications caused by it, makes ectopic pregnancy a very current problem, frequently encountered in Obstetrics-Gynecology clinics

The aim of this study is to compare how risk factors and management can influence the incidence and the risk of recurrence of ectopic pregnancy.

This paper presents a prospective case-control study for 65 patients, who have been diagnosed serologically and ultrasonically. In the present study, the most common risk factors involved were: pelvic inflammatory disease $(46 \%)$, ectopic pregnancy $(20 \%)$, smoking $(85 \%)$, abortions $(55 \%)$, and abdominal surgery $(43 \%)$. In the group of patients studied, patients required surgical and medical treatment, and also a management of expectation.

The risk factors that influence recurrence were smoking (100\%), pelvic inflammatory disease (84.6\%), abortions $(53.8 \%)$, abdominal surgery $(46 \%)$. By the type of surgery (laparoscopy or laparotomy), the risk of recurrence varies between 6 and $10 \%$ and does not seem to be influenced by it.
\end{abstract}

Keywords: incidence of ectopic pregnancy, recurrence of ectopic pregnancy, anxiety after ectopic pregnancy

\section{INTRODUCTION}

In recent years, there has been an increase in the incidence of ectopic pregnancy in women of reproductive age, explained by the existence of many risk factors underlying its occurrence and whose share has increased recently. Both physiological and pathological history are among the risk factors for ectopic pregnancy $(1,2)$.

Complications resulting from voluntary termination of pregnancy, infections, as well as postabortion endometritis can cause irreversible morphological lesions that favor, in the future, the occurrence of ectopic pregnancy. Specialized studies show that personal pathological history of ectopic pregnancy increases the risk of a new ectopic pregnancy (3). Appendectomy, cholecystectomy, tubal ligation, tubal plasties, pelvic interventions (ovarectomies, myomectomies), as well as cesarean operations result in the appearance of intra-abdominal adhesions that can change the tubal anat- omy, favoring the appearance of ectopic pregnancies (4). The risk of ectopic pregnancy is doubled by the use of tobacco. Nicotine alters the number and affinity of adrenergic receptors, alters tubal motility and inhibits ciliary activity (5). In vitro fertilization and the use of ovulation stimulators cause endocrine imbalances $(6,7)$.

Immunological tests in conjunction with ultrasound (transabdominal and transvaginal) can make the diagnosis very accurately. All women in the reproductive period who have the Crossen triad (abdominal pain, metrorrhagia and amenorrhea) should undergo paraclinical tests to confirm or refute the diagnosis of ectopic pregnancy (8).

Curative behavior includes both medical treatment and conservative or radical surgical therapy. From the point of view of surgery, the treatment is classified into classic and laparoscopic interventions, and from the point of view of the integrity of the female genital tract, the interventions can be 
conservative (linear salpingostomy and tubal evacuation of the conception product).

The study aims to compare how the risk factors and treatment methods can influence the recurrent risk, reducing anxiety.

\section{MATERIAL AND METHOD}

This paper presents a prospective case-control study, conducted in the Bucharest Maternity Hospital - Bucharest between January 1, 2018 and December 31, 2018.

During the study, 65 patients with ectopic pregnancy were hospitalized. The diagnosis was established on the basis of clinical examination and specialized investigations, in accordance with current protocols.

Several parameters were evaluated: age, parity, risk factors, location, treatment, psychological impact of ectopic pregnancy on patients.

Inclusion criteria were:

- Pregnancy test positive;

- The absence of ultrasound images of intrauterine sac, or extrauterine ovarian sac with or without embryonic elements, or equivocal intrauterine ultrasound images;

- hospitalized patients;

- Treatment-compliant patients.

All data were collected from hospitalization sheets and have been processed using Microsoft Excel. All data obtained were processed while maintaining the confidentiality of patients' personal data. Every patient that was enrolled in our study signed an informed consent, and the study was approved by the Ethical Committee.

\section{RESULTS}

As the youngest patient was 18 years old and the oldest 44 years old, the group of patients was divided into age groups.

In the study group there is an incidence of $3.8 \%$ of ectopic pregnancy in relation to the number of births in the evaluated period (65 ectopic pregnancies per 1,693 births).

The evaluation of the data shows a much lower incidence of ectopic pregnancy after 40 years $(9 \%)$ and before 20 years $(6 \%)$ compared to other age groups.

The first physiological antecedent that was followed in this case was multiparity. Thus, in the studied group there were 24 nulliparous, 22 primiparous and 19 multiparous.

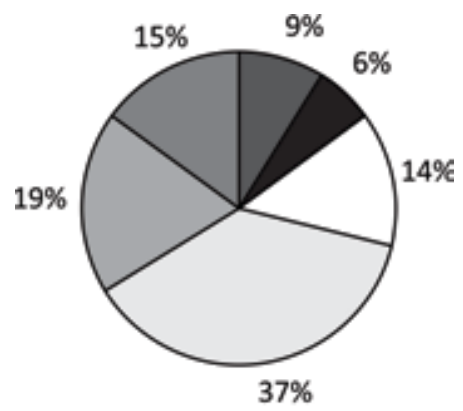

15-19 ㅁ20-24 ㅁ25-29

FIGURE 1. Distribution by age groups of the ectopic pregnancy

TABLE 1. The incidence of ectopic pregnancy in relation to the age and parity of patiens

\begin{tabular}{|c|c|c|c|c|}
\hline Age groups & $\begin{array}{c}\text { Number } \\
\text { of cases }\end{array}$ & $\begin{array}{c}\text { Nulli- } \\
\text { parous }\end{array}$ & $\begin{array}{c}\text { Primi- } \\
\text { parous }\end{array}$ & $\begin{array}{c}\text { Multi- } \\
\text { parous }\end{array}$ \\
\hline$<20$ years & 4 & 2 & 2 & 0 \\
\hline $20-29$ years & 33 & 17 & 9 & 7 \\
\hline $30-39$ years & 22 & 4 & 9 & 9 \\
\hline over 40 years & 6 & 1 & 2 & 3 \\
\hline
\end{tabular}

The vast majority of risk factors for ectopic pregnancy are included in the pathological history. Among these risk factors, the present study assessed number of abortions, number of ectopic pregnancies, number of abdominal surgeries, smoking, using of ovulation stimulants, sexually transmitted diseases.

Number of abortions $-55 \%$ of patients had a history of one or more abortions.

TABLE 2. Distribution of cases of ectopic pregnancy according to previous abortions

\begin{tabular}{|c|c|c|}
\hline Number of abortions & Number of cases & Percentages \\
\hline 0 & 29 & $44.61 \%$ \\
\hline 1 & 12 & $18.46 \%$ \\
\hline 2 & 6 & $9.23 \%$ \\
\hline 3 & 8 & $12.30 \%$ \\
\hline$\geq 4$ & 10 & $15.38 \%$ \\
\hline Total & 65 & \\
\hline \multicolumn{2}{|l}{} \\
\hline
\end{tabular}

Number of ectopic pregnancies in the history The presence of ectopic pregnancy in a personal pathological history in $20 \%$ (13 cases) of hospitalized patients.

Abdominal surgeries - The present study highlights the presence of a history of abdominal surgery (mostly appendectomy and cesarean section) in 30 patients $(43 \%)$.

TABLE 3. Distribution of ectopic pregnancy cases according to the type of surgery

\begin{tabular}{|c|c|c|}
\hline Intervention & $\begin{array}{c}\text { Number of } \\
\text { cases }\end{array}$ & Percentages \\
\hline Cesarean section & 17 & $26 \%$ \\
\hline Other interventions & 11 & $16 \%$ \\
\hline $\begin{array}{c}\text { Cesarean section and other } \\
\text { interventions }\end{array}$ & 10 & $15 \%$ \\
\hline
\end{tabular}


Smoking - A worryingly large number of patients in the study, $55(85 \%)$, used tobacco and only $10(15 \%)$ were non-smokers.

Ovulation stimulators - Of the total group of 65 patients, three patients $(4.61 \%)$ used ovulation stimulants.

TABLE 4. Risk factors in the occurrence of ectopic pregnancy

\begin{tabular}{|c|c|c|}
\hline Risk factors & $\begin{array}{c}\text { Number of } \\
\text { cases }\end{array}$ & Percentages \\
\hline Abdominal surgery & 28 & $43.07 \%$ \\
\hline $\begin{array}{c}\text { Pelvic inflammatory } \\
\text { disease }\end{array}$ & 30 & $46.15 \%$ \\
\hline $\begin{array}{c}\text { Sexually transmitted } \\
\text { diseases }\end{array}$ & 4 & $6.15 \%$ \\
\hline Smoking & 55 & $84.61 \%$ \\
\hline Ovulation stimulants & 3 & $4.61 \%$ \\
\hline Abortions & 36 & $55.38 \%$ \\
\hline Nulliparous & 24 & $36.92 \%$ \\
\hline $\begin{array}{c}\text { Ectopic pregnancies in } \\
\text { the history }\end{array}$ & 13 & $20 \%$ \\
\hline
\end{tabular}

Among the risk factors for ectopic pregnancy, smoking is the most common culprit in the etiology (55 cases), followed by abortions, pelvic inflammatory disease and surgery, while sexually transmitted diseases ( 4 cases) and ovulation stimulants ( 3 cases) were the least common.

In the group of patients studied, the localization was predominantly tubal and a pregnancy with ovarian localization. No abdominal pregnancies were reported. At the same time, there was a case of hemoperitoneum in a patient with a uterine curettage on request performed previously (7 days before) for 7 weeks of pregnancy. In that case we could not classify as heterotopic pregnancy, not having sufficient anatomical-pathological data for this.

TABLE 5. Anatomical location of ectopic pregnancy

\begin{tabular}{|c|c|c|}
\hline Anatomical location & Number of cases & Percentages \\
\hline Ampullary & 20 & $30.76 \%$ \\
\hline Infundibular & 32 & $49.23 \%$ \\
\hline Interstitial & 2 & $3.07 \%$ \\
\hline Isthmic & 5 & $7.69 \%$ \\
\hline Corneal & 1 & $1.53 \%$ \\
\hline Ovarian & 1 & $1.53 \%$ \\
\hline Cervical & 2 & $3.07 \%$ \\
\hline Post-cesarean scar & 2 & $3.07 \%$ \\
\hline
\end{tabular}

The investigations used to confirm the diagnosis of ectopic pregnancy in the Bucur Maternity Clinic are ultrasound and $\beta \mathrm{HCG}$ dosing.

The therapeutic management of ectopic pregnancies diagnosed in patients in the study group is mainly surgical (69\% of patients), followed by medical management (25\%), pregnancy aspiration $(4 \%)$ and expectation management $(2 \%)$.

At the level of the studied group, 13 cases from 65 were recurrent. How risk factors influenced the recurrence of ectopic pregnancy in these cases is reflected in table 6 .

TABLE 6. The recurrence of ectopic pregnancy according to risk factors

\begin{tabular}{|c|c|c|}
\hline Risk factors & $\begin{array}{c}\text { Number } \\
\text { of cases }\end{array}$ & Percentages \\
\hline Smoking & 13 & $100 \%$ \\
\hline Pelvic inflammatory disease & 11 & $84.61 \%$ \\
\hline Abortions & 7 & $53.84 \%$ \\
\hline Abdominal surgery & 6 & $46.15 \%$ \\
\hline
\end{tabular}

The recurrence of ectopic pregnancy depending on treatment is $16 \%$ (11 patients) after surgical therapy and 3\% (2 patients) after medical therapy.

TABLE 7. The recurrence of ectopic pregnancy depending on treatment

\begin{tabular}{|c|c|c|}
\hline Treatment & $\begin{array}{c}\text { Number of } \\
\text { cases }\end{array}$ & Percentages \\
\hline Salpingectomy & 5 & $7 \%$ \\
\hline Salpingostomy & 6 & $9 \%$ \\
\hline Methotrexate & 2 & $3 \%$ \\
\hline
\end{tabular}

According to the type of intervention it is $6 \%$ (4 patients) after laparoscopic intervention and $10 \%$ (7 patients) after laparotomy. The risk of recurrence of ectopic tubal pregnancy does not seem to be influenced by the surgical procedure.

The present study revealed in 95\% (61 cases) the presence of mild anxiety, especially in patients with recurrence of ectopic pregnancy.

TABLE 8. Anxiety after ectopic pregnancy

\begin{tabular}{|c|c|c|}
\hline Anxiety & $\begin{array}{c}\text { Number of } \\
\text { cases }\end{array}$ & Percentages \\
\hline First ectopic pregnancy & 48 & $73.84 \%$ \\
\hline Recurrent ectopic pregnancy & 13 & $20 \%$ \\
\hline Total & 61 & \\
\hline
\end{tabular}

It is imperative to support the patient and family, provide informational materials on the consequences of ectopic pregnancy and future fertility, display an empathic attitude, encourage the patient to express doubts, fears, and the involvement of the psychologist and patient support groups on supporting the patient and her family.

\section{DISCUSSIONS}

The discussions are generated following the comparative study carried out between the group of evaluated patients hospitalized in Bucur Maternity and the specialized literature. 
The occurrence of ectopic pregnancy in the studied group of patients is predominantly in primiparous and multiparous patients (a total of 41 cases) compared to nulliparous patients (24 cases), and as an age range the study showed that ectopic pregnancy is a frequent pathology of reproductive age. In this case our results were not similar to those of other studies. (9)

In the present study, the most common risk factors involved in the etiopathogenesis of this condition were: smoking, abortions, a history of pelvic inflammatory disease, abdominal surgery and ectopic pregnancy. The risk factors included in our study were similar to those highlighted in the literature (10-15). Due to the diverse etiopathogenesis of ectopic pregnancy, prevention should address the risk factors involved in its occurrence: active and correct treatment of inflammation and genital infections, eradication of endometriosis, treatment of sexual hormonal disorders, combating induced abortions, avoidance of gynecological adhesions in surgery conservative, as well as a rigorous selection of cesarean-terminated births (16).

As a location of the ectopic pregnancy, the tubal location predominates in $91 \%$ of cases (59 patients), the non-tubular location amounting to $9 \%$ (6 patients), in accordance with the literature $(17,18)$.

The risk of recurrence of ectopic pregnancy appear to be influenced by the mode of treatment, similar to the literature (19). In our study, recurrence of ectopic pregnancy was $16 \%$ (11 patients) after surgical therapy and 3\% (2 patients) after medical therapy.

According to the type of intervention -laparoscopic or laparotomy -the risk of recurrence of ectopic tubal pregnancy does not seem to be influenced by the surgical procedure. Other studies reveal a lower risk for laparoscopy $(20,21)$.

The diagnosis of ectopic pregnancy can have a major impact on a woman's mental health, espe-

\section{REFERENCES}

1. Shaw JL, Dey SK, Critchley HO, Horne AW. Current knowledge of the aetiology of human tubal ectopic pregnancy. Hum Reprod Update. 2010 Jul-Aug;16(4):432-44.

2. Panelli DM, Phillips $\mathrm{CH}$, Brady PC. Incidence, diagnosis and management of tubal and nontubal ectopic pregnancies: a review. Fertil Res Pract. 2015 Oct 15;1:15.

3. Butts S, Sammel M, Hummel A, Chittams J, Barnhart K. Risk factors and clinical features of recurrent ectopic pregnancy: a case control study. Fertil Steril. 2003 Dec;80(6):1340-4.

4. Barnhart KT. Clinical practice. Ectopic pregnancy. N Engl J Med. 2009 Jul 23;361(4):379-87.

5. Saraiya M, Berg CJ, Kendrick JS, Strauss LT, Atrash HK, Ahn YW. Cigarette smoking as a risk factor for ectopic pregnancy. Am J Obstet Gynecol. 1998 Mar;178(3):493-8. cially if the conception took place after much effort. Pregnancy loss can have devastating effects on physical and mental health by needing the unconditional support of family, partner, friends and the support provided by medical staff. Post-traumatic stress is all the greater as the woman has suffered a recurrence of ectopic pregnancy, which significantly reduces the chances of a later conception $(22,23)$. Published studies on the psychological impact of ectopic pregnancy on patients are few, the medical world being focused on the discovery of new treatment methods and surgical techniques for early detection and treatment with minimal physical consequences of ectopic pregnancy, leaving in second place, somehow, the assessment of posttraumatic stress felt by the patient. These studies showed that psychological morbidity is higher in patients who have had ectopic pregnancy compared to patients who have had an abortion, with anxiety and even depression persisting even 3 months after the triggering event $(20 \%$ showing signs of anxiety, and 5\% signs of depression $(24,25)$.

\section{CONCLUSIONS}

Even if the study group was not numerically significant, most of the evaluated indicators were in line with the results published in the literature.

Ectopic pregnancy is the leading cause of maternal death during the first trimester of pregnancy. A better understanding of risk can help prevent its occurrence.

With earlier diagnosis, medical therapy with methotrexate can be offered and surgery avoided in some women, though the best regimen remains unclear. In the surgical management of ectopic pregnancy, the benefits of salpingectomy over salpingostomy are uncertain. Although there have been advances in the management of ectopic pregnancy there are still questions to be answered.
6. Perkins KM, Boulet SL, Kissin DM, Jamieson DJ; National ART Surveillance (NASS) Group. Risk of ectopic pregnancy associated with assisted reproductive technology in the United States, 2001-2011. Obstet Gynecol. 2015 Jan;125(1):70-78.

7. Gelbaya TA. Short and long-term risks to women who conceive through in vitro fertilization. Hum Fertil (Camb). 2010 Mar; 13(1):19-27.

8. Emerson DS, Cartier MS, Altieri LA, Felker RE, Smith WC, Stovall TG, Gray LA. Diagnostic efficacy of endovaginal color Doppler flow imaging in an ectopic pregnancy screening program. Radiology. 1992 May;183(2):413-20.

9. Zhang D, Shi W, Li C, Yuan JJ, Xia W, Xue RH, Sun J, Zhang J. Risk factors for recurrent ectopic pregnancy: a case-control study. BJOG. 2016 Sep;123 Suppl 3:82-9. 
10. Marion LL, Meeks GR. Ectopic pregnancy: History, incidence, epidemiology, and risk factors. Clin Obstet Gynecol. 2012 Jun;55(2):376-86.

11. Li C, Zhao WH, Zhu Q, Cao SJ, Ping H, Xi X, Qin GJ, Yan MX, Zhang D, Qiu J, Zhang J. Risk factors for ectopic pregnancy: a multi-center case-control study. BMC Pregnancy Childbirth. 2015 Aug 22;15:187.

12. Joesoef MR, Westrom L, Reynolds G, Marchbanks P, Cates W. Recurrence of ectopic pregnancy: the role of salpingitis. Am J Obstet Gynecol. $1991 \mathrm{Jul} ; 165(1): 46-50$.

13. Kutluay L, Vicdan K, Turan C, Batioğlu S, Oğuz S, Gökmen O. Tubal histopathology in ectopic pregnancies. Eur J Obstet Gynecol Reprod Biol. 1994 Nov;57(2):91-4.

14. Coste J, Bouyer J, Ughetto S, Gerbaud L, Fernandez H, Pouly JL, Job-Spira N. Ectopic pregnancy is again on the increase. Recent trends in the incidence of ectopic pregnancies in France (19922002). Hum Reprod. 2004 Sep;19(9):2014-8.

15. Petrini A, Spandorfer S. Recurrent Ectopic Pregnancy: Current Perspectives. Int J Womens Health. 2020 Aug 4;12:597-600.

16. Mann LM, Kreisel K, Llata E, Hong J, Torrone EA. Trends in Ectopic Pregnancy Diagnoses in United States Emergency Departments, 2006-2013. Matern Child Health J. 2020 Feb;24(2):213-221.

17. Kirk E, Bottomley C, Bourne T. Diagnosing ectopic pregnancy and current concepts in the management of pregnancy of unknown location. Hum Reprod Update. 2014 Mar-Apr;20(2):250-61.

18. Carusi D. Pregnancy of unknown location: Evaluation and management. Semin Perinatol. 2019 Mar;43(2):95-100.

Conflict of interest: none declared

Financial support: none declared
19. Irani M, Robles A, Gunnala V, Spandorfer SD. Unilateral Salpingectomy and Methotrexate Are Associated With a Similar Recurrence Rate of Ectopic Pregnancy in Patients Undergoing In Vitro Fertilization. J Minim Invasive Gynecol. 2017 Jul-Aug;24(5):777-782.

20. Ellaithy M, Asiri M, Rateb A, Altraigey A, Abdallah K. Prediction of recurrent ectopic pregnancy: A five-year follow-up cohort study. Eur J Obstet Gynecol Reprod Biol. 2018 Jun;225:70-78.

21. Farquhar CM. Ectopic pregnancy. Lancet. 2005 Aug 13-19; 366(9485):583-91.

22. Farren J, Jalmbrant M, Ameye L, Joash K, Mitchell-Jones N, Tapp S, Timmerman D, Bourne T. Post-traumatic stress, anxiety and depression following miscarriage or ectopic pregnancy: a prospective cohort study. BMJ Open. 2016 Nov 2;6(11):e011864.

23. Dikmen-Yildiz P, Ayers S, Phillips L. Depression, anxiety, PTSD and comorbidity in perinatal women in Turkey: A longitudinal populationbased study. Midwifery. 2017 Dec;55:29-37.

24. de Bennetot M, Rabischong B, Aublet-Cuvelier B, Belard F, Fernandez H, Bouyer J, Canis M, Pouly JL. Fertility after tubal ectopic pregnancy: results of a population-based study. Fertil Steril. 2012 Nov;98(5):1271-6.e1-3.

25. San Lazaro Campillo I, Meaney S, McNamara K, O'Donoghue K. Psychological and support interventions to reduce levels of stress, anxiety or depression on women's subsequent pregnancy with a history of miscarriage: an empty systematic review. BMJ Open. 2017 Sep 7;7(9):e017802. 